\title{
A forma de aplicação da uréia e dos resíduos vegetais afeta a disponibilidade de nitrogênio
}

\author{
The addition form of crop residues and urea interfers on nitrogen availability
}

\author{
Paulo Roberto Ernani ${ }^{1}$ Luís Sangoi ${ }^{2}$ Vanderlei Adilson Lech $^{3} \quad$ Clair Rampazzo $^{4}$
}

\section{RESUMO}

O método de aplicação dos resíduos vegetais e dos fertilizantes nitrogenados pode afetar as reações do nitrogênio no solo, principalmente no plantio direto. O presente trabalho objetivou avaliar esses efeitos na disponibilidade de $N$ para o milho em dois solos, em casa-de-vegetação. Combinações de métodos (ausência, incorporada ou na superfície) de adição de

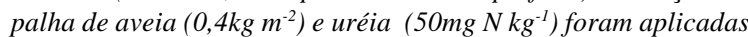
em unidades experimentais $\left(7 \mathrm{dm}^{3}\right.$ vaso $\left.^{-1}\right)$ de dois solos, perfazendo um fatorial $3 \times 3 \times 2$. O milho foi semeado no dia da aplicação dos tratamentos e as plantas foram cultivadas durante trinta dias, sobre um Neossolo e um Nitossolo, respectivamente com 50 e $520 \mathrm{~g} \mathrm{~kg}^{-1}$ de argila e 8 e $48 \mathrm{~g} \mathrm{~kg}^{-1}$ de matéria orgânica. A aplicação de palha de aveia, principalmente sobre a superfície do solo, beneficiou o desenvolvimento das plantas, possivelmente pela manutenção de maior quantidade de umidade nos solos. A aplicação de uréia não afetou nenhum parâmetro vegetal no solo argiloso, talvez porque a decomposição da matéria orgânica liberou mais $N$ do que a imobilização ocasionada durante a decomposição da palha; no solo arenoso, entretanto, a uréia foi benéfica quando incorporada ao solo, e prejudicial quando adicionada na superfície, provavelmente devido à toxidez de amônia. Dessa forma, o efeito da decomposição da palha de aveia na disponibilidade de $N$ foi função do teor de matéria orgânica original do solo.

Palavras-chave: Zea mays, imobilização de $N$, mineralização de $N$, cobertura do solo.

\section{ABSTRACT}

Management of both crop residues and nitrogen fertilizers affects soil $N$ reactions especially on no-till systems.
The magnitude of these effects on $N$ availability to maize was evaluated in a greenhouse study. Combinations of oat straw and urea (absence, soil incorporated or surface applied) were added to experimental units (7-dm $\mathrm{dm}^{3}$ per pot) of two soils, in a $3 \times 3 \times 2$ factorial combination. Plants were sown just following treatments addition, and grown for thirty days in two soils (Typic Quartzipsammnets and Humic Hapludox) with 50 and $520 \mathrm{~g} \mathrm{~kg}^{-1}$ clay and 8 and $48 \mathrm{~g} \mathrm{~kg}^{-1}$ organic matter respectively. Oat straw, especially when surface applied, had a positive effect on plant growth, most likely caused by increases on soil water retention. Urea application, however, had no effect on any plant parameter on the clayey soil probably because the amount of $N$ released from soil organic matter mineralization was greater than that immobilized during residue decomposition. On the sandy soil, however, urea was beneficial when incorporated into the soil, but was detrimental when surface applied possibly due to ammonia toxicity. Thus, soil organic matter content influences the effect of oat straw decomposition on $N$ availability to maize.

Key words: Zea mays, $N$ immobilization, $N$ mineralization, soil covering.

\section{INTRODUÇÃO}

A imobilização de $\mathrm{N}$ pelos microorganismos ocorre após a adição ao solo de resíduos orgânicos com alta relação $\mathrm{C}: \mathrm{N}$, principalmente quando são decompostos rapidamente. A imobilização ganhou maior destaque após o advento do sistema de plantio direto em função do cultivo de

${ }^{1}$ Engenheiro Agrônomo, PhD, Professor da Universidade do Estado de Santa Catarina (UDESC), CP 281, 88520-000, Lages, SC, Bolsista do Conselho Nacional de Desenvolvimento Científico e Tecnológico (CNPq). E-mail: a2pre@cav.udesc.br. Autor para correspondência.

${ }^{2}$ Engenheiro Agrônomo, PhD, Professor da UDESC, Bolsista do CNPq. E-mail: a21s@ cav.udesc.br.

${ }^{3}$ Engenheiro Agrônomo, aluno do Curso de Mestrado em Ciência do Solo da UDESC, Bolsista da Coordenação de Aperfeiçoamento de Pessoal de Nível Superior (CAPES).

${ }^{4}$ Aluno do Curso de Agronomia da UDESC, Bolsista de Iniciação Científica do CNPq. 
gramíneas hibernais para produção de massa verde e cobertura do solo. A aveia preta (Avena strigosa) tem sido a espécie mais cultivada na região Sul do Brasil para esse objetivo, principalmente em função da rusticidade, grande produção de biomassa, e baixo custo das sementes. A parte aérea da aveia, no período de dessecação, possui relação $\mathrm{C}: \mathrm{N}$ que varia de aproximadamente 35:1 (AITA et al., 2001; HEINRICHS et al., 2001; BORTOLINI et al., 2002) a 49:1 (AMADO et al., 2000) e, por isso, pode imobilizar N (AITA et al., 2001; HEINRICHS et al., 2001), com conseqüências na diminuição da absorção de $\mathrm{N}$ e no rendimento de grãos da cultura semeada após a dessecação (DA ROS \& AITA, 1996, AITA et al., 2001; HEINRICHS et al., 2001).

$O$ efeito da imobilização sobre o rendimento vegetal depende, entretanto, da quantidade de $\mathrm{N}$ imobilizada, da disponibilidade de $\mathrm{N}$ no solo, e da época de maior imobilização relativamente à demanda vegetal, e esses fatores são influenciados por muitas variáveis. A taxa de decomposição dos resíduos vegetais é maior quando eles são incorporados ao solo (SCHOMBERG et al., 1994; AMADO et al., 2000; SAINJU \& SINGH, 2001) do que quando deixados na superfície, apesar dessa última forma de manejo reduzir a evaporação de água (REICOSKY et al., 1995) e as flutuações bruscas de temperatura do solo (SALTON \& MIELNICZUK, 1995). A quantidade e a época em que os adubos nitrogenados são aplicados ao solo também pode afetar a imobilização ou a liberação de $\mathrm{N}$. A aplicação parcial do $\mathrm{N}$ durante a dessecação das plantas de cobertura de solo tem por objetivo acelerar a decomposição desses resíduos. Essa técnica, entretanto, tem proporcionado menores rendimentos de milho que o método tradicional de fertilização, no qual o $\mathrm{N}$ é aplicado na semeadura e em cobertura (BASSO \& CERETTA, 2000; CERETTA et al., 2002; BORTOLINI et al., 2002).

As plantas de milho apresentam maior demanda por $\mathrm{N}$ a partir do estádio com 4 a 5 folhas expandidas. O suprimento insuficiente de $\mathrm{N}$ pelo solo, neste período, pode reduzir a diferenciação do número de óvulos nos primórdios da espiga e o número de espigas por planta, e com isso afetar negativamente o rendimento de grãos (SCHREIBER et al., 1998). Como a imobilização de $\mathrm{N}$ é mais intensa nas primeiras semanas após a dessecação das plantas de cobertura de solo (AMADO et al., 2000), recomendase retardar a época de semeadura da cultura econômica em, pelo menos, trinta dias para evitar que a época de maior imobilização coincida com o período de maior demanda das plantas por N. Com o transcorrer da decomposição, a relação $\mathrm{C}: \mathrm{N}$ diminui e a quantidade de $\mathrm{N}$ imobilizada passa a ser menor que a mineralizada. A melhor maneira de evitar um possível prejuízo causado pela imobilização no rendimento vegetal consiste, no entanto, em adicionar uma quantidade maior de $\mathrm{N}$ na semeadura da cultura de interesse econômico.

Esse trabalho objetivou avaliar o efeito do manejo dos resíduos culturais de aveia e da forma de aplicação da uréia sobre a disponibilidade de $\mathrm{N}$ e o desenvolvimento inicial de milho, em dois solos com diferentes texturas e conteúdos de matéria orgânica.

\section{MATERIAL E MÉTODOS}

O experimento foi conduzido em casa de vegetação, em Lages, SC, no ano de 2000. Utilizaramse amostras de um Nitossolo Vermelho (NV), coletadas da camada arável de uma área com vegetação campestre nativa, em Lages, e de um Neossolo quartzarênico (NQ), proveniente do município de Araranguá. O NV apresentou $48 \mathrm{~g} \mathrm{~kg}^{-1}$ de matéria orgânica (M.O.), $520 \mathrm{~g} \mathrm{~kg}^{-1}$ de argila, $\mathrm{pH}$ $4,9, \mathrm{P}=3,0 \mathrm{mg} \mathrm{dm}^{-3}$, e $\mathrm{K}=110 \mathrm{mg} \mathrm{dm}^{-3}$; o NQ tinha $8 \mathrm{~g} \mathrm{~kg}^{-1}$ de M.O., $50 \mathrm{~g} \mathrm{~kg}^{-1}$ de argila, $\mathrm{pH} 5,0, \mathrm{P}=4,0 \mathrm{mg}$ $\mathrm{dm}^{-3}$, e $\mathrm{K}=70 \mathrm{mg} \mathrm{dm}{ }^{-3}$.

Os tratamentos consistiram da combinação de métodos de cobertura do solo (sem palha, palha de aveia aplicada na superfície, e palha incorporada ao solo) com formas de adubação nitrogenada (sem uréia, uréia na superfície, e uréia incorporada) em dois solos catarinenses. $\mathrm{O} \mathrm{N}$ foi adicionado na dose de $50 \mathrm{mg} \mathrm{kg}^{-1}$. Os resíduos da parte aérea de aveia preta foram coletados no estádio de florescimento, tinham uma relação $\mathrm{C}: \mathrm{N}$ de $36: 1$, e foram aplicados numa quantidade equivalente a $4,0 \mathrm{t} \mathrm{ha}^{-1}$ de matéria seca, considerando a área superficial do solo. Anteriormente à aplicação dos tratamentos, os solos receberam calcário dolomítico para elevar o pH em água até 6,0, e, a seguir, foram incubados por três meses, dentro de sacos plásticos, na temperatura ambiente. Cada tratamento teve três repetições, distribuídas no delineamento completamente casualizado.

O milho (híbrido C 909) foi semeado em janeiro, junto com a aplicação do $\mathrm{N}$ e da palha. Utilizaram-se vasos plásticos com $20 \mathrm{~cm}$ de diâmetro, os quais foram preenchidos com solo até o volume de $7 \mathrm{dm}^{3}$, perfazendo $6,0 \mathrm{~kg}$ para o solo argiloso e $8,0 \mathrm{~kg}$ para o solo arenoso. Anteriormente à semeadura, cada unidade experimental recebeu $\mathrm{KCl}$, na dose de $100 \mathrm{mg} \mathrm{kg}^{-1}$ de K, e superfosfato triplo, nas doses de $100 \mathrm{e} 150 \mathrm{mg} \mathrm{kg}^{-1} \mathrm{de}$ P para os solos arenoso e argiloso, respectivamente. Após a emergência, efetuou-se o desbaste, deixando-se seis plantas por vaso, as quais foram cultivadas durante 
trinta dias. Os solos foram mantidos com umidade de aproximadamente $80 \%$ do teor de água retido na capacidade de campo, por meio de adições diárias de água destilada com base na massa total dos vasos.

Por ocasião da colheita, determinou-se altura, matéria seca, e $\mathrm{N}$ acumulado na parte aérea. A altura foi determinada em três plantas por vaso, considerando a distância entre o nível do solo e a extremidade da última folha com expansão completa. Todas as plantas de cada vaso foram cortadas ao nível do solo e secas em estufa a $60^{\circ} \mathrm{C}$, até atingirem massa constante. Após a pesagem, a parte aérea foi moída, digerida com mistura de ácido sulfúrico concentrado e água oxigenada, a quente, e nos extratos determinouse o $\mathrm{N}$ total após destilação por meio de arraste de vapores, em aparelho semi-micro Kjeldahl. O N acumulado foi calculado considerando-se a massa seca e a concentração de $\mathrm{N}$ da fitomassa.

No solo, determinaram-se os teores de $\mathrm{N}$ mineral (amônio + nitrito + nitrato) e carbono microbiano, em amostras coletadas no final do cultivo. $\mathrm{O} \mathrm{N}$ mineral foi extraído com $\mathrm{KCl} 1,0 \mathrm{~mol} \mathrm{~L}^{-1}$, na relação solo:solução de $1: 10$, e determinado pelo procedimento descrito anteriormente. $\mathrm{O} \mathrm{C}$ microbiano foi determinado por meio do método da irradiaçãoextração, descrito em FERREIRA et al. (1999), e aplicação do fator de conversão de 2,78 , proposto por VANCE et al. (1987).

Os resultados foram avaliados estatisticamente por meio da análise de variância considerando o fatorial $3 \times 3 \times 2$ (palha, uréia e solo). A magnitude dos efeitos dos tratamentos frente ao erro experimental foi testada através do teste F. Os valores de $\mathrm{F}$ para efeitos principais e interações foram considerados significativos a $5 \%$ de probabilidade de erro $(\mathrm{P}<0,05)$. Quando a significância estatística foi alcançada, a comparação entre as médias foi realizada pelo teste de Duncan, a 5\% de probabilidade. Quando não houve interação entre os fatores, foram apresentadas e discutidas somente as médias dos efeitos principais.

\section{RESULTADOS E DISCUSSÃO}

O carbono microbiano foi afetado diferentemente em cada solo em função da forma de aplicação da uréia e da palha de aveia (Tabela 1). No solo argiloso (NV), a palha e o $\mathrm{N}$ aumentaram o $\mathrm{C}$ microbiano em aproximadamente 2,3 vezes em relação à testemunha (sem palha e sem $\mathrm{N}$ ), mas a forma de aplicação dos mesmos (incorporados ou na superfície) não teve influência. No solo arenoso (NQ), nenhum tratamento afetou o $\mathrm{C}$ microbiano, cuja média foi de $44 \mu \mathrm{g} \mathrm{g}^{-1}$, aproximadamente cinco vezes menor

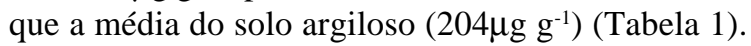
Os valores do solo argiloso foram similares aos encontrados por VARGAS \& SCHOLLES (2000) num Podzólico Vermelho-Escuro do Rio Grande do Sul. A baixa população microbiana e a ausência de incremento na mesma no NQ pode ter limitado a imobilização de $\mathrm{N}$ e, com isso, o $\mathrm{N}$ mineralizado dos resíduos orgânicos se torna todo disponível às plantas.

A adição de palha favoreceu o desenvolvimento das plantas e a absorção de $\mathrm{N}$, porém em diferentes magnitudes em função do método de aplicação (Tabelas 2 e 3). No solo arenoso, a adição de palha incrementou a altura das plantas e o acúmulo de $\mathrm{N}$ pelas mesmas, independentemente do método de aplicação, assim como aumentou o rendimento de matéria seca da parte aérea do milho, principalmente quando ela foi aplicada sobre a superfície. No solo argiloso, entretanto, o efeito benéfico da palha sobre esses parâmetros ocorreu somente quando ela foi aplicada na superfície (Tabelas 2 e 3), fenômeno também observado por BORTOLINI et al. (2000) em plantas jovens de milho cultivadas em vasos. O efeito benéfico da manutenção da palha na superfície do solo pode estar relacionado à manutenção de maior quantidade de água no solo, pois a cobertura proporcionada pelos resíduos vegetais reduz a temperatura do solo (BORTOLUZZI \& ELTZ, 2000) e a evaporação, e, com isso, aumenta a absorção de água (REICOSKY et al., 1995) e o transporte e a absorção de nutrientes, inclusive do N. Esse fenômeno

Tabela 1 - Efeito da adição e da forma de aplicação da uréia e da palha de aveia preta sobre o carbono microbiano em solos com diferentes conteúdos de argila e matéria orgânica. Média de duas épocas de semeadura do milho e três repetições.

\begin{tabular}{lccc}
\hline \multirow{2}{*}{$\begin{array}{l}\text { Forma de } \\
\text { aplicação da } \\
\text { palha }\end{array}$} & \multicolumn{3}{c}{ Forma de aplicação do N } \\
\cline { 2 - 4 } & Ausência & Incorporado & Superficial \\
\hline \multicolumn{3}{c}{$\mu \mathrm{g} \mathrm{g}^{-1}$ Solo argiloso } \\
Ausência & $93 \mathrm{~B} \mathrm{~b}$ & $156 \mathrm{AB} \mathrm{b}$ & $206 \mathrm{~A} \mathrm{a}$ \\
Incorporada & $266 \mathrm{~A} \mathrm{a}$ & $252 \mathrm{~A} \mathrm{a}$ & $189 \mathrm{~A} \mathrm{a}$ \\
Superficial & $201 \mathrm{~A} \mathrm{a}$ & $227 \mathrm{~A} \mathrm{ab}$ & $250 \mathrm{~A} \mathrm{a}$ \\
& & Solo arenoso & \\
Ausência & 34 & 38 & 32 \\
Incorporada & 66 & 74 & 30 \\
Superficial & 39 & 36 & 43 \\
\hline
\end{tabular}

Médias seguidas por mesma letra, maiúscula na linha e minúscula na coluna, para cada variável, dentro de cada solo, não diferem significativamente pelo teste de Duncan, em nível de 5\%. Inexistência de letras significa ausência de diferença estatística. Os solos diferiram entre si em todas combinações de tratamentos. 
Tabela 2 - Efeito da adição e do método de aplicação da palha de aveia preta e da uréia sobre o $\mathrm{N}$ acumulado na parte aérea e altura de planta de milho em solos com diferentes conteúdos de argila e de matéria orgânica.

\begin{tabular}{|c|c|c|c|c|}
\hline \multirow[b]{2}{*}{ Método } & \multicolumn{2}{|c|}{ Solo arenoso } & \multicolumn{2}{|c|}{ Solo argiloso } \\
\hline & Altura & $\mathrm{N}$ acumulado & Altura & $\mathrm{N}$ acumulado \\
\hline & $(\mathrm{cm})$ & $\left(\mathrm{mg} \mathrm{vaso}{ }^{-1}\right)$ & $(\mathrm{cm})$ & $\left(\mathrm{mg} \mathrm{vaso}{ }^{-1}\right)$ \\
\hline & & & & \\
\hline Ausência & $62 \mathrm{~b}$ & $188 \mathrm{~b}$ & $52 \mathrm{~b}$ & $119 \mathrm{~b}$ \\
\hline Incorporada & $65 \mathrm{a}$ & $235 \mathrm{a}$ & $51 \mathrm{~b}$ & $114 \mathrm{~b}$ \\
\hline Superficial & $64 \mathrm{a}$ & $237 \mathrm{a}$ & $58 \mathrm{a}$ & $159 \mathrm{a}$ \\
\hline & & & & \\
\hline Ausência & $61 \mathrm{~b}$ & $139 \mathrm{~b}$ & 53 & 125 \\
\hline Incorporada & $66 \mathrm{a}$ & $277 \mathrm{a}$ & 54 & 134 \\
\hline Superficial & $63 \mathrm{~b}$ & $244 \mathrm{a}$ & 54 & 133 \\
\hline
\end{tabular}

Médias sucedidas pela mesma letra na coluna, para cada variável dentro de cada efeito principal e do mesmo solo, não diferem significativamente pelo teste de Duncan, em nível de 5\%. Inexistência de letras significa ausência de diferença estatística. Os solos diferiram entre si em todas combinações de tratamentos, para todas variáveis.

ocorre mesmo em experimentos com vasos quando eles recebem água apenas uma vez por dia, como foi o caso do presente estudo, pois em casa-de-vegetação a evaporação é bastante intensa quando a temperatura e a umidade não são controladas. No solo arenoso, além desse efeito, a palha, independente do método de aplicação, também contribuiu para o fornecimento de N.

A imobilização de $\mathrm{N}$ foi pequena e menor que a mineralização desse nutriente. Mesmo tendo havido imobilização de $\mathrm{N}$ nos tratamentos com palha, como pode ser observado pela quantidade de $\mathrm{N}$ mineral remanescente no solo após os cultivos (Tabela 4), a adição desses resíduos aumentou o acúmulo de $\mathrm{N}$ pelas plantas, provavelmente devido aos efeitos benéficos na umidade do solo, na mineralização da matéria orgânica nativa (efeito priming) e, talvez, na melhoria de alguma propriedade física. No solo arenoso, o efeito benéfico da adição de palha sobre a altura das plantas e absorção de $\mathrm{N}$ pode também ser explicado pela inexistência de imobilização, fenômeno já discutido anteriormente.

O efeito da aplicação de nitrogênio na altura de planta, quantidade de nitrogênio acumulada, e rendimento de matéria seca de milho variou com o tipo de solo (Tabelas 2 e 3). No arenoso, a adição de uréia aumentou o acúmulo de $\mathrm{N}$ na parte aérea das plantas, independentemente do método de aplicação. A altura de planta, entretanto, somente aumentou nos tratamentos com uréia incorporada, porque naqueles com uréia na superfície do solo, as plantas apresentaram sintomas visuais iguais aos ocasionados

Tabela 3 - Efeito da adição e do método de aplicação da palha de aveia preta e da uréia no rendimento de matéria seca de milho em solos com diferentes conteúdos de argila e matéria orgânica.

\begin{tabular}{|c|c|c|c|c|c|c|}
\hline \multirow{2}{*}{ Palha } & \multicolumn{3}{|c|}{ Solo arenoso } & \multicolumn{3}{|c|}{ Solo argiloso } \\
\hline & Sem N & $\mathrm{N}$ incorp. & $\mathrm{N}$ superf. & Sem N & $\mathrm{N}$ incorp. & $\mathrm{N}$ superf. \\
\hline & & & & 3,6 & 3,6 & 3,9 \\
\hline Sem palha & $3,0 \mathrm{C} \mathrm{c}$ & $5,5 \mathrm{~A} \mathrm{~b}$ & $4,3 \mathrm{~B} \mathrm{~b}$ & - & $3,4 \mathrm{~b}$ & - \\
\hline Palha incorporada & $4,6 \mathrm{~B} \mathrm{~b}$ & $5,8 \mathrm{~A} \mathrm{~b}$ & $4,8 \mathrm{~B} \mathrm{~b}$ & - & $3,2 \mathrm{~b}$ & - \\
\hline Palha na superfície & $5,7 \mathrm{~B} \mathrm{a}$ & $6,6 \mathrm{~A} \mathrm{a}$ & $6,4 \mathrm{~A} \mathrm{a}$ & - & $4,4 \mathrm{a}$ & - \\
\hline
\end{tabular}

Médias seguidas pela mesma letra, maiúscula na linha e minúscula na coluna, para cada variável dentro de cada efeito principal e do mesmo solo, não diferem significativamente pelo teste de Duncan, em nível de 5\%. Inexistência de letras significa ausência de diferença estatística. (1) No solo argiloso, não houve interação entre os métodos de aplicação do $\mathrm{N}$ e da palha, e, portanto, foram fornecidas as médias dos tratamentos principais. Inexistência de letras significa ausência de diferença estatística. Na média dos tratamentos principais, os solos diferiram entre si em todas as combinações.

Ciência Rural, v.35, n.2, mar-abr, 2005. 
por toxidez de amônia. Em solos com baixa capacidade de troca de cátions, como a desse NQ, grande parte do amônio, oriundo da hidrólise da uréia aplicada sobre a superfície, não é adsorvido eletrostaticamente pelas cargas negativas e, portanto, volatiliza na forma de amônia e pode prejudicar a germinação e o desenvolvimento inicial das plantas (OUYANG et al., 1998). No solo argiloso, a aplicação de uréia não influenciou nenhum parâmetro de planta (Tabelas 2 e 3), provavelmente devido à grande contribuição da mineralização do $\mathrm{N}$ da matéria orgânica nativa, aliada à pequena imobilização de nitrogênio. Em lavouras cultivadas há vários anos, entretanto, a imobilização normalmente tem sido maior que a mineralização do N (AITA et al., 2001; HEINRICHS et al., 2001), principalmente nos períodos iniciais subseqüentes à adição de resíduos vegetais com alta relação C:N. CAMARGO et al. (1997) verificaram que aproximadamente $64 \%$ e $84 \%$ do $\mathrm{N}$ de dez solos gaúchos haviam sido mineralizados, respectivamente, ao final de quatro e oito semanas.

A forma de aplicação da palha e da uréia influenciou a quantidade de $\mathrm{N}$ mineral (amônio + nitrito + nitrato) remanescente após os cultivos, nos dois solos (Tabela 4). A incorporação da palha aumentou o $\mathrm{N}$ mineral remanescente nos solos provavelmente devido à sua mineralização, pois essa prática favorece a decomposição dos resíduos vegetais (AMADO et al., 2000). A aplicação de uréia também aumentou o $\mathrm{N}$ mineral remanescente após o cultivo. No solo argiloso, o $\mathrm{N}$ mineral foi maior quando o fertilizante foi incorporado do que quando aplicado na superfície, provavelmente em decorrência do efeito

Tabela 4 - Efeitos do manejo da palha de aveia preta e do método de aplicação de uréia sobre a quantidade de nitrogênio mineral (amônio + nitrato) remanescente nos solos após a colheita das plantas de milho cultivadas durante trinta dias.

\begin{tabular}{lcc}
\hline & Arenoso & Argiloso \\
\hline Manejo da palha & \multicolumn{2}{c}{$\mathrm{mg} \mathrm{de} \mathrm{N} \mathrm{kg}^{-1}$} \\
Sem palha & $21 \mathrm{~b}$ & $50 \mathrm{c}$ \\
Palha incorporada & $31 \mathrm{a}$ & $87 \mathrm{a}$ \\
Palha superfície & $21 \mathrm{~b}$ & $63 \mathrm{~b}$ \\
Manejo do N & & \\
Sem N & $15 \mathrm{~b}$ & $38 \mathrm{c}$ \\
N incorporado & $32 \mathrm{a}$ & $88 \mathrm{a}$ \\
N superficial & $27 \mathrm{a}$ & $73 \mathrm{~b}$ \\
\hline
\end{tabular}

Médias seguidas pela mesma letra na coluna, para cada variável dentro de cada efeito principal e do mesmo solo, não diferem significativamente pelo teste de Duncan, em nível de 5\%. Os solos diferiram entre si em todos tratamentos. benéfico sobre a mineralização do $\mathrm{N}$ orgânico nativo (SAMPAIO \& SALCEDO, 1993) e da maior volatilização de amônia que ocorre quando a uréia não é incorporada (LARA CABEZAS et al., 2000).

\section{CONCLUSÕES}

Em solos arenosos com pouca matéria orgânica, o C microbiano é baixo e não é influenciado pela adição de palha de aveia. Nessa situação, a imobilização de $\mathrm{N}$ não acontece, o $\mathrm{N}$ mineralizado da palha é liberado para as plantas e, mesmo assim, é importante suprir $\mathrm{N}$ às plantas por meio de fertilizantes nitrogenados. Em solos argilosos com alta matéria orgânica, a imobilização de $\mathrm{N}$ decorrente da adição de palha de aveia é pequena, inferior ao $\mathrm{N}$ mineralizado desse resíduo ou da matéria orgânica nativa, e a resposta à adição de fertilizantes nitrogenados é inexistente, pelo menos no primeiro cultivo após a mobilização do solo. A manutenção de palha de aveia na superfície do solo beneficia o desenvolvimento das plantas e a absorção de N, provavelmente por manter mais umidade no solo.

\section{REFERÊNCIAS BIBLIOGRÁFICAS}

AITA, C. et al. Plantas de cobertura de solo como fonte de nitrogênio ao milho. Revista Brasileira de Ciência do Solo, v.25, n.1, p.157-165, 2001.

AMADO, T.J. et al. Leguminosas e adubação mineral como fontes de nitrogênio para o milho em sistemas de preparo do solo. Revista Brasileira de Ciência do Solo, v.24, n.1, p.179-189, 2000.

BASSO, C.J.; CERETTA, C.A. Manejo do nitrogênio no milho em sucessão a plantas de cobertura de solo sob plantio direto. Revista Brasileira de Ciência do Solo, v.24, n.4, p.905-915, 2000 .

BORTOLINI, C.G. et al. Efeito de resíduos de plantas jovens de aveia preta em cobertura no crescimento inicial do milho. Pesquisa Agropecuária Gaúcha, v.6, n.1, p.83-88, 2000.

BORTOLINI, C.G. et al. Sistemas de aplicação de nitrogênio e seus efeitos sobre o acúmulo de N na planta de milho. Revista Brasileira de Ciência do Solo, v.26, n.2, p.361-366, 2002.

BORTOLUZZI, E.C.; ELTZ, F.L.F. Efeito do manejo mecânico da palhada de aveia preta sobre a cobertura, temperatura, teor de água no solo e emergência da soja em sistema plantio direto. Revista Brasileira de Ciência do Solo, v.24, n.2, p.449-457, 2000.

CAMARGO, F.A.O. et al. Potencial de mineralização do nitrogênio em solos do Rio Grande do Sul. Revista Brasileira de Ciência do Solo, v.21, n.4, p.575-579, 1997.

CERETTA, C.A. et al. Manejo da adubação nitrogenada na sucessão aveia preta/milho, no sistema plantio direto. Revista Brasileira de Ciência do Solo, v.26, n.1, p.163-171, 2002. 
DA ROS, A.O.; AITA, C. Efeito de espécies de inverno na cobertura do solo e fornecimento de nitrogênio ao milho em plantio direto. Revista Brasileira de Ciência do Solo, v.20, n.1, p.135$140,1996$.

FERREIRA, A.S. et al. Utilização de microondas na avaliação da biomassa microbiana do solo. Revista Brasileira de Ciência do Solo, v.23, n.4, p.991-996, 1999.

HEINRICHS, R. et al. Cultivo consorciado de aveia e ervilhaca: relação $\mathrm{C} / \mathrm{N}$ da fitomassa e produtividade do milho em sucessão. Revista Brasileira de Ciência do Solo, v.25, n.2, p.331-340, 2001.

LARA CABEZAS, W.A.R. et al. Balanço da adubação nitrogenada sólida e fluída de cobertura na cultura do milho, em sistema plantio direto no triângulo mineiro. Revista Brasileira de Ciência do Solo, v.24, n.2, p.363376,2000

OUYANG, D. et al. Phytotoxicity of banded urea amended with triple superphosphate and potassium chloride. Agronomy Journal, v.90, n.3, p.734-739, 1998.

REICOSKY, D.C. et al. Soil organic matter changes resulting from tillage and biomass production. Journal of Soil and Water Conservation, v.50, n.2, p.253-261, 1995.

SALTON, J.C.; MIELNICZUK, J. Relações entre sistemas de preparo, temperatura e umidade de um
Podzólico vermelho-escuro de Eldorado do Sul (RS). Revista Brasileira de Ciência do Solo, v.19, n.3, p.333319, 1995.

SAMPAIO, E.V.S.B.; SALCEDO, I.H. Mineralização e absorção por milheto do nitrogênio do solo, da palha de milho- $\left({ }^{15} \mathrm{~N}\right)$ e da uréia- $\left({ }^{15} \mathrm{~N}\right)$. Revista Brasileira de Ciência do Solo, v.17, n.3, p.423-429, 1993

SAINJU, U.M.; SINGH, B.P. Tillage, cover crop, and kill-planting date effects on corn yield and soil nitrogen. Agronomy Journal, v.93, n.4, p.878-886, 2001

SCHOMBERG, H.H. et al. Decomposition and nitrogen dynamics of crop residues quality and water effects. Soil Science Society of America Journal, v.58, n.2, p.372-381, 1994.

SCHREIBER, H.A. et al. Irrigation and nitrogen effects on sweet corn row number at various growth stages. Soil Science, v.135, n.1, p.135136, 1998.

VANCE, E.D. et al. An extraction method for measuring soil microbial biomass C. Soil Biology \& Biochemistry, v.19, n.3, p.697-702, 1987

VARGAS, L.K.; SCHOLLES, D. Biomassa microbiana e produção de C-CO e $\mathrm{N}$ mineral de um podzólico vermelho-escuro submetido a diferentes sistemas de manejo. Revista Brasileira de Ciência do Solo, v.24, n.1, p.35-42, 2000. 